Egypt. Acad. J. biolog. Sci., 4 (1):115 - 122 (2011)

Email: egyptianacademic@yahoo.com

A. Entomology

Received: 11/4/2011

ISSN: 1687-8809

www.eajbs.eg.net

\title{
Heat Unit Requirements for Development of the Pink Bollworm Pectinophora gossypiella (Saund.)
}

\author{
Yones, M. S. ${ }^{1}$; Abd EIRahman, H. A. ${ }^{2}$; Abou Hadid A. F. ${ }^{3}$; Arafat, S. M. ${ }^{1}$ \\ and Dahi, H. F. ${ }^{4}$
}

1- National Authority for Remote sensing and Space Sciences (NARSS), 23, Josef proztito St. Elnozha Elgedida - P.O. Box 1564 Alf maskan Cairo, Egypt monayones@yahoo.com

2- Faculty of Science, Ain Shams University, Egypt.

3- Minstry of Agriculture, Egypt.

4- Plant Protection Research Institute, Giza, Egypt.

\begin{abstract}
The present study was carried out under four constant temperatures $(20,25$, 30 and $35^{\circ} \mathrm{C}$ each $\pm 1^{\circ} \mathrm{C}$ ) when the Pink Bollworm, Pectinophora gossypiella (Saund.) larvae, were fed on artificial diet. The time required for embryogensis, larval duration and pupal duration decreased as the temperatures increased from 20 to $35^{\circ} \mathrm{C}$. The lower thresholds of development $\left(\mathrm{t}_{0}\right)$ were $9.91,14.07,9.57$ and $12.18^{\circ} \mathrm{C}$ for eggs, larvae, pupae and pre-oviposition period, respectively. The average accumulated heat units required for development was $72.11,166.38$, 248.70 and 26.83 degree-days for egg, larvae, pupae and pre-oviposition period, respectively. The lower threshold of development $\left(\mathrm{t}_{0}\right)$ to complete a generation was $12.03^{\circ} \mathrm{C}$. The average accumulated heat units required for a generation was 499.71 degree-days. The kind of food had non-significant effect for heat requirements. The thermal units required to complete the development of different stages to complete one generation, as well as helping in the design of development indexes, determining the times required for these stages under fluctuating temperatures in field and forecasting system for establishment and develop the non chemical methods for the pink bollworm IPM program.
\end{abstract}

Keywords: Heat Unit, Pink Bollworm

\section{INTRODUCTION}

Cotton is one of the major economic crops in Egypt. The most of yield and quality losses are caused by insect pests, specially the pink bollworm, Pectinophora gossypiella (Saund.) as it attack the fruiting part (squares, flowers and green bolls).

Wagner et al., (1984) described the developmental rates as a function of temperature. However, little attempts have been made on the use of temperature accumulation as an aid in forecasting the various stages of this pest (Hashem et al., 1997 and Dahi, 2003).

During the cotton-growing season, chemical control still one of the major tool to control bollworms. The control of this pest depended on the stages, which are found outside the fruit bodies, mainly egg, newly hatched larvae as well as moths. So, it is important to determine the generations of the pest and the time of insecticidal application with the appearance of the target stage. The number of 
insecticide applications can often be markedly reduced by the missing use, for treatment at the economic threshold level.

To obtain information on the temperature threshold $\left(\mathrm{t}_{0}\right)$ and temperature accumulation for $P$. gossypiella, studies were conducted on four constant temperatures. Degree-days represent the accumulation of heat units over a minimum temperature for a 24 -hour period. Below this minimum temperature, no development took place, but above it, heat units are accumulated towards development (Pedigo, 1991).

This study was conducted to monitor this cycle and to determine its corresponding temperature requirements.

\section{MATERIAL AND METHODS}

Eggs of P. gossypiella were obtained from the Division of bollworms, Plant Protection Research Institute, resulting from susceptible strains reared in the laboratory for at least four generations on an artificial diet.

All the P. gossypiella stages were kept under four constant temperatures $\left(20,25,30\right.$ and $\left.35^{\circ} \mathrm{C}\right)$ to determine the rate of development. Eggs were transferred to glass vials $(2.0 \times 7.5 \mathrm{~cm})$; four replicates of 25 eggs / each were used for each of the situations to be tested. Observations were made daily to record the time of hatchability. The incubation period and the embryo development rates were estimated. To study the larval development, 100 newly hatched larvae (4 replicates) were transferred, each in a separate glass tube $(7.5 \times 2.5 \mathrm{~cm}$. $) 25$ larvae/replicate. The larvae were left in the vials until pupation. Daily observations were made to count the pupated larvae, larval developmental rate and duration was estimated.

Newly formed pupae were collected on the same day of pupation and placed in the glass tube (one pupa for each tube) and plugged tightly with a piece of cotton. Four replicates (each of 25 pupae) were placed at each tested temperature and observed daily till adult emergence. After being sexed, the newly emerged moths of each group resulted from the same temperature were isolated in pairs, one pair for each kept in a separate tube $(15 \mathrm{~cm}$ long $5 \mathrm{~cm}$ diam.) opened at each ends, contain a small piece of absorbent cotton wool previously soaked in $20 \%$ sucrose solution for adult feeding solution. The two ends of each tube were covered with, secured rubber band, and a small strip of muslin cloths as a suitable site of oviposition. Five replicates, each has 2 adults $(1$ male +1 female), were placed at each tested temperature. Daily observations were made to record the adult survival.

Duration of different stages and other biological aspects were record of each temperature degree. Data obtained in the present work were subjected to statistical analysis by t-test.

The rate of development for P. gossypiella stages (incubation period, larval duration, pupal duration, pre-oviposition period and period of one generation) were determined by the simple formula ( $1 / \mathrm{t} \times 100)$ for the four constant temperatures.

The obtained data concerned the effectiveness of different constant temperature degrees on both immature and adult stages of $P$. gossypiella were subjected to statistical analysis where the theoretical development thresholds $\left(t_{0}\right)$ and the accumulated thermal units $(\mathrm{K})$ were determined according to the regression formula:

$$
\mathrm{Y}=\mathrm{a}+\mathrm{bx}
$$


$\left(\mathrm{t}_{0}\right)=-\mathrm{a} / \mathrm{b} \quad \& \quad \mathrm{~K}=1 / \mathrm{b}$

On the other hand, thermal units required for complete development of each stage was determined according to the equation of thermal summation (Blunk, 1923):

$\mathrm{K}=\mathrm{y}\left(\mathrm{T}-\mathrm{t}_{0}\right)$

Where $\mathrm{y}=$ developmental duration of a given stage; $\mathrm{T}=$ temperature in degree centigrade; $\mathrm{t}_{0}=$ lower threshold of development and $\mathrm{K}=$ thermal units (DegreeDays (DD's)).

\section{RESULTS AND DISCUSSION}

\section{Egg stag:}

Table (1) indicated that the average embryogenesis period varied from 7.0 days at $20^{\circ} \mathrm{C}$ to 2.38 days at $35^{\circ} \mathrm{C}$. The lower threshold of development $\left(\mathrm{t}_{0}\right)$ for the egg stage was $9.91{ }^{\circ} \mathrm{C}$ as indicated in Fig. (1).

The same Table showed that the average thermal units required for eggs development till hatching was 72.11 DD's as determined by the thermal summation equation $\mathrm{K}=\mathrm{y}(\mathrm{T}-9.91)$.

The four observed values for eggs rate of development at the four tested temperature degrees, gave also a remarkable good fit to the calculated temperature -velocity line having the formula $\mathrm{Y}=1.38 \mathrm{X}-13.71$ (Fig.1).

Table 1: Development of $P$. gossypiella eggs under different constant temperatures and its thermal requirements.

\begin{tabular}{|c|c|c|c|c|c|c|}
\hline \multirow{2}{*}{$\begin{array}{l}\text { Temp. } \\
\left({ }^{\circ} \mathrm{C}\right)\end{array}$} & \multicolumn{2}{|c|}{ Observed } & \multicolumn{2}{|c|}{ Expected } & \multirow{2}{*}{$\left({ }^{\circ} \mathbf{t}_{0} \mathbf{C}\right)$} & \multirow{2}{*}{$\begin{array}{l}\text { Degree Days } \\
\text { (DD's) }\end{array}$} \\
\hline & $\begin{array}{c}\text { Incubation } \\
\text { period } \\
\text { (days } \pm \text { S.E) }\end{array}$ & $\begin{array}{c}\text { Rate of } \\
\text { development } \%\end{array}$ & $\begin{array}{c}\text { Incubation } \\
\text { period (days) }\end{array}$ & $\begin{array}{c}\text { Rate of } \\
\text { development } \%\end{array}$ & & \\
\hline 20 & $7.0 \pm 0.13 \mathrm{a}$ & 14.28 & 7.16 & 13.97 & \multirow{4}{*}{9.91} & 70.63 \\
\hline 25 & $4.79 \pm 0.21 \mathrm{~b}$ & 20.87 & 4.78 & 20.89 & & 72.28 \\
\hline 30 & $3.71 \pm 0.05 \mathrm{c}$ & 26.95 & 3.59 & 27.82 & & 74.53 \\
\hline 35 & $2.83 \pm 0.10 \mathrm{~d}$ & 35.33 & 2.78 & 34.74 & & 71.00 \\
\hline Average & & & & & & 72.11 \\
\hline L.S.D 1\% & & & 0.67 & & & \\
\hline
\end{tabular}

The values having the same letters vertically are non significant for different.

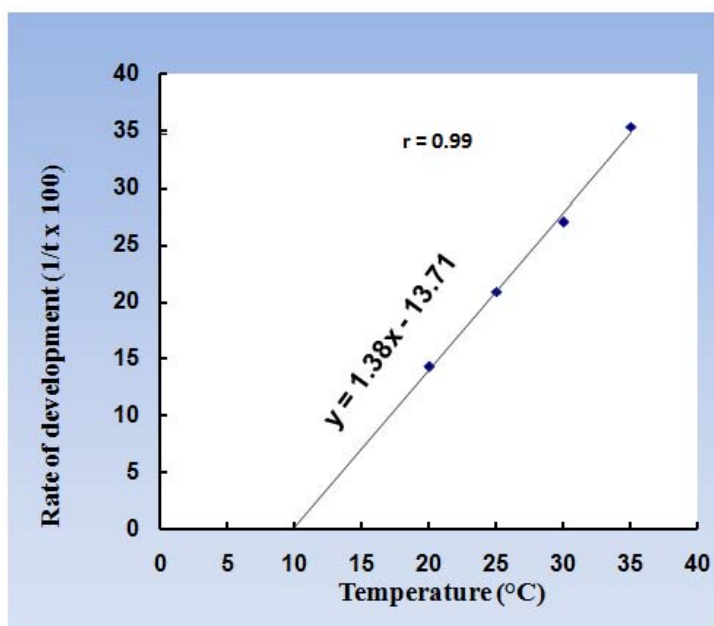

Fig. (1): The regression line of the relation between the rate of development of $P$. gossypiella egg and different constant temperatures. 


\section{Larval stage:}

Concerning the effects of the four tested constant temperatures on the larval duration of $P$. gossypiella, it was noticed generally that the larval duration period decreased as temperature increased where the average durations were 29.68, 13.97, 10.87 and 7.82 days at $20,25,30$ and $35{ }^{\circ} \mathrm{C}$, respectively (Table 2).Statistically, there are significant differences between all the values of larval durations at all temperature degrees.

The developmental zero $\left(\mathrm{t}_{0}\right)$ for this stage was $14.07^{\circ} \mathrm{C}$ as illustrated graphically by extrapolation in Fig. (2). Data in the same Table refer that the average of thermal heat units for $P$. gossypiella larvae was 166.38 DD's as estimated by the thermal summation equation $\mathrm{K}=\mathrm{y}(\mathrm{T}-14.07)$.

The four observed values for the pupal rate of developmental gave a remarkable good fit to the calculated temperature - velocity line having the formula $\mathrm{Y}=0.61 \mathrm{x}-8.52$ Fig. (2).

Table 2: Development of $P$. gossypiella larvae under different constant temperatures and its thermal requirements.

\begin{tabular}{|c|c|c|c|c|c|c|}
\hline \multirow{2}{*}{$\begin{array}{l}\text { Temp. } \\
\left({ }^{\circ} \mathrm{C}\right)\end{array}$} & \multicolumn{2}{|c|}{ Observed } & \multicolumn{2}{|c|}{ Expected } & \multirow[t]{2}{*}{$\left({ }^{\circ} \mathbf{t}_{0} \mathbf{C}\right)$} & \multirow{2}{*}{$\begin{array}{c}\text { Degree } \\
\text { Days } \\
\text { (DD's) }\end{array}$} \\
\hline & $\begin{array}{l}\text { Larval duration } \\
\quad(\text { days } \pm \text { S.E) }\end{array}$ & $\begin{array}{c}\text { Rate of } \\
\text { development \% }\end{array}$ & $\begin{array}{l}\text { Larval duration } \\
\text { (days) }\end{array}$ & $\begin{array}{c}\text { Rate of } \\
\text { development \% }\end{array}$ & & \\
\hline 20 & $29.68 \pm 0.33 \mathrm{a}$ & 3.37 & 27.93 & 3.58 & \multirow{5}{*}{14.07} & 176.00 \\
\hline 25 & $13.97 \pm 0.50 \mathrm{~b}$ & 7.16 & 15.13 & 6.61 & & 152.69 \\
\hline 30 & $10.87 \pm 0.31 \mathrm{c}$ & 9.20 & 10.37 & 9.64 & & 173.16 \\
\hline 35 & $7.82 \pm 0.15 \mathrm{~d}$ & 12.78 & 7.89 & 12.66 & & 163.67 \\
\hline Average & & & & & & 166.38 \\
\hline L.S.D $1 \%$ & & & 1.70 & & & \\
\hline
\end{tabular}

The values having the same letters vertically are non significant for different.

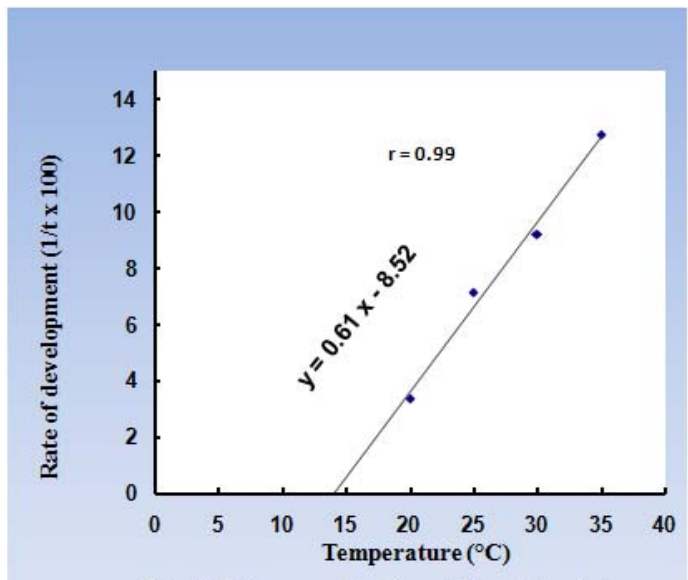

Fig. (2): The regression line of the relation between the rate of development of $P$. gossypiella larvae and different constant temperatures.

\section{Pupal stage :}

Data in Table (3) and Fig. (3) show the relation between P. gossypiella pupal duration and constant temperatures $20,25,30$ and $35^{\circ} \mathrm{C}$. The relationship as obviously occurred and indicated that the required time for completion of pupal development decreased as the temperature increased. The means of pupal duration 
were $24.17,16.11,11.89$ and 9.88 days at $20,25,30$ and $35^{\circ} \mathrm{C}$, respectively. Statistical analysis indicated that there are significant relationships between all values of pupal stage at all temperatures.

The lower threshold of pupal development was calculated and illustrated in Fig. (3), it was found to be $9.57^{\circ} \mathrm{C}$. The average of thermal units in degree - days required for the completion of development of this stage was 248.70 DD's. The four observed values of pupal rate of development at the constant temperatures $(20$, 25,30 and $35^{\circ} \mathrm{C}$ ), gave a remarkable good fit to the calculated temperature velocity line having the formula $\mathrm{Y}=0.40 \mathrm{x}-3.86$ (Fig. 3).

Table 3: Development of $P$. gossypiella pupae under different constant temperatures and its relation with thermal requirements.

\begin{tabular}{|c|c|c|c|c|c|c|}
\hline \multirow{2}{*}{$\begin{array}{l}\text { Temp. } \\
\left({ }^{\circ} \mathrm{C}\right)\end{array}$} & \multicolumn{2}{|c|}{ Observed } & \multicolumn{2}{|c|}{ Expected } & \multirow[t]{2}{*}{$\left({ }^{\circ} \mathrm{t}_{0} \mathrm{C}\right)$} & \multirow{2}{*}{$\begin{array}{l}\text { Degree Days } \\
\text { (DD's) }\end{array}$} \\
\hline & $\begin{array}{l}\text { Pupal duration } \\
\text { (days } \pm \text { S.E) }\end{array}$ & $\begin{array}{c}\text { Rate of development } \\
\%\end{array}$ & $\begin{array}{c}\text { Pupal duration } \\
\text { (days) }\end{array}$ & $\begin{array}{c}\text { Rate of } \\
\text { development } \%\end{array}$ & & \\
\hline 20 & $24.17 \pm 0.28 \mathrm{a}$ & 4.14 & 23.86 & 4.19 & 9.57 & 252.09 \\
\hline 25 & $16.11 \pm 0.34 \mathrm{~b}$ & 6.21 & 16.10 & 6.21 & & 248.57 \\
\hline 30 & $11.89 \pm 0.35 \mathrm{c}$ & 8.41 & 12.16 & 8.22 & & 242.91 \\
\hline 35 & $9.88 \pm 0.31 \mathrm{~d}$ & 10.12 & 9.76 & 10.24 & & 251.24 \\
\hline Average & & & & & & 248.70 \\
\hline L.S.D 1\% & & & 1.56 & & & \\
\hline
\end{tabular}

The values having the same letters vertically are non significant for different.

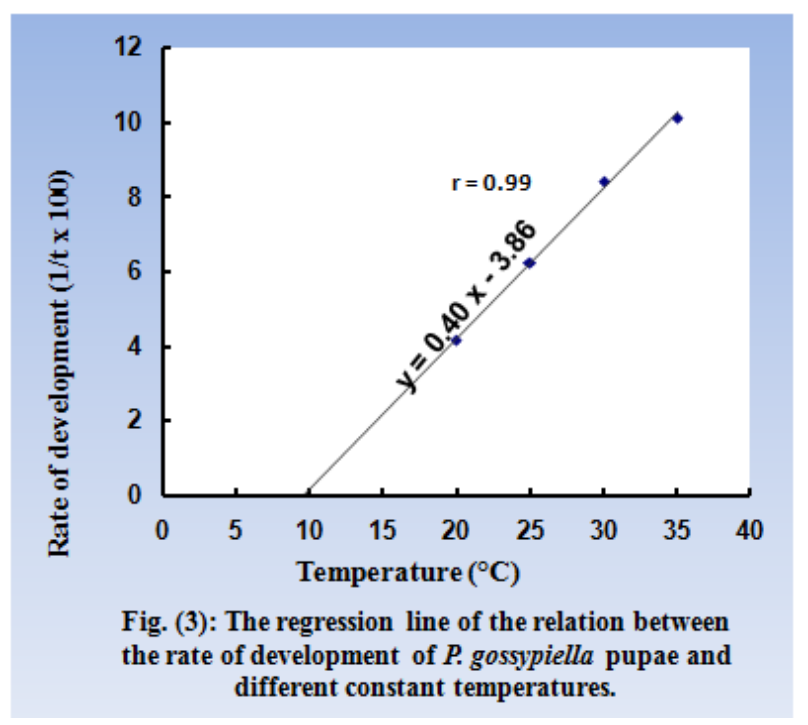

\section{Adult stage: \\ Pre-oviposition period}

Data in Table (4) show that the mean time required for maturation of the ovaries and starting egg laying, decreased as the temperature increased from 4.66 days at $20^{\circ} \mathrm{C}$ to 1.20 days at $35^{\circ} \mathrm{C}$. Statistically, There were significant differences between pre-oviposition period recorded at $20^{\circ} \mathrm{C}$ and the values at 25,30 and 35 ${ }^{\circ} \mathrm{C}$, whereas, there were no significant differences between pre-oviposition period at 25,30 and $35^{\circ} \mathrm{C}$. 
The lower threshold of development was $12.18^{\circ} \mathrm{C}$. The average of total thermal units was 26.83 DD's as calculated by thermal summation equation $\mathrm{K}=\mathrm{y}$ $(\mathrm{T}-12.18)$. The four observed values for this period rate of development at 20, 25, 30 and $35^{\circ} \mathrm{C}$, gave also a remarkable good fit to the calculated temperature velocity line having the formula $\mathrm{Y}=3.88 \mathrm{x}-49.79$ (Fig.4).

Table 4: Duration of $P$. gossypiella pre-oviposition period under different constant temperatures and its thermal requirements.

\begin{tabular}{|c|c|c|c|c|c|c|}
\hline \multirow{2}{*}{$\begin{array}{l}\text { Temp. } \\
\left({ }^{\circ} \mathrm{C}\right)\end{array}$} & \multicolumn{2}{|c|}{ Observed } & \multicolumn{2}{|c|}{ Expected } & \multirow[t]{2}{*}{$\left({ }^{\circ} \mathrm{t}_{0} \mathrm{C}\right)$} & \multirow{2}{*}{$\begin{array}{c}\text { Degree Days } \\
\text { (DD's) }\end{array}$} \\
\hline & $\begin{array}{c}\text { Pre-oviposition } \\
\text { period } \\
\text { (days } \pm \text { S.E) }\end{array}$ & $\begin{array}{c}\text { Rate of } \\
\text { development \% }\end{array}$ & $\begin{array}{c}\text { Pre-oviposition } \\
\text { period (days) }\end{array}$ & $\begin{array}{c}\text { Rate of } \\
\text { development \% }\end{array}$ & & \\
\hline 20 & $4.66 \pm 0.36 \mathrm{a}$ & 21.45 & 3.57 & 27.95 & 12.18 & 33.50 \\
\hline 25 & $1.74 \pm 0.06 \mathrm{~b}$ & 57.47 & 2.11 & 47.39 & & 21.21 \\
\hline 30 & $1.51 \pm 0.11 \mathrm{~b}$ & 66.22 & 1.49 & 66.83 & & 25.99 \\
\hline 35 & $1.20 \pm 0.04 \mathrm{~b}$ & 83.33 & 1.16 & 86.27 & & 26.62 \\
\hline Average & & & & & & 26.83 \\
\hline L.S.D 1\% & & & 0.92 & & & \\
\hline
\end{tabular}

The values having the same letters vertically are non significant for different.

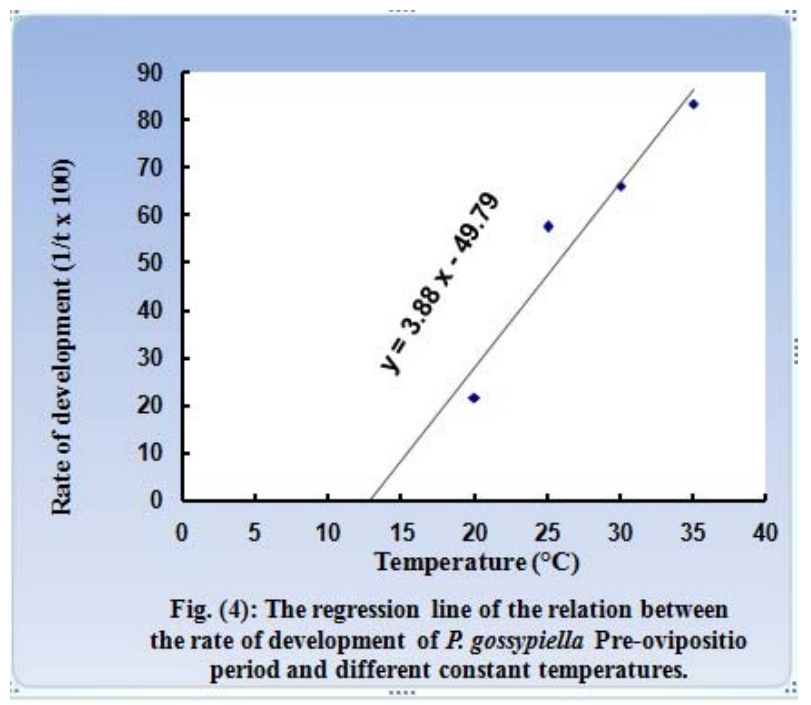

\section{The generation}

The mean duration of total period of generation at different constant temperature regimes could be calculated using the total of mean duration of different developmental stages (i.e. incubation period, larval stage, pupal stage and pre-oviposition period). Theoretically, the result obtained from this method shows an approximate value for mean duration of generation at different constant temperature regimes.

In the present study, data in Table (5) indicates that the mean duration of generation for P. gossypiella were $65.51,36.61,27.98$ and 21.73 days at 20, 25, 30 and $35^{\circ} \mathrm{C}$, respectively. Data reveled that the increasing of temperature accelerated the developmental rate of $P$. gossypiella where it reached the maximum velocity at $35^{\circ} \mathrm{C}$. Statistical analysis indicated that there are significant relationships between values of mean generation periods and temperatures.

Thermal summation method, represents the hyperbolic relationship between temperature and developmental times given by equation: $\mathrm{Y}(\mathrm{T}-12.03)=$ 
499.71DD's, that drive from the linear regression equation: $\mathrm{Y}=0.20 \mathrm{x}-2.42(\mathrm{r}=$ $0.99)$. The lower threshold of development $\left(t_{0}\right)$ that could be estimated graphically by extrapolation from the Fig. (5) was $12.03^{\circ} \mathrm{C}$.

These results agreed with the findings obtained by Kajanshikov (1946) who found that the linear relationship between temperature and rate of development can be expressed by the formula $\mathrm{K}=\mathrm{y}\left(\mathrm{T}-\mathrm{t}_{0}\right)$. Gergis et al., (1994) investigated the relationship between temperature and developmental rates for the cotton leafworm under field and laboratory conditions. They reported that the different stages of $S$. littoralis completed their development at the range of temperatures from 15-32.5 ${ }^{\circ} \mathrm{C}$, under this conditions where the threshold of development and thermal units were also estimated.

The results in the present study are in agreement with Gergis et al., (1990) on Earias insulana; Abdel-Hafez et al., 1993 on Pectinophora gossypiella and Dahi 2003 on Spodoptera littoralis.

Table 5: Duration of $P$. gossypiella generation under different constant temperatures and its thermal requirements.

\begin{tabular}{|c|c|c|c|c|c|c|}
\hline \multirow{2}{*}{$\begin{array}{l}\text { Temp. } \\
\left({ }^{\circ} \mathrm{C}\right)\end{array}$} & \multicolumn{2}{|c|}{ Observed } & \multicolumn{2}{|c|}{ Expected } & \multirow[b]{2}{*}{$\left(\mathbf{t}_{0}{ }^{\circ} \mathbf{C}\right)$} & \multirow{2}{*}{$\begin{array}{l}\text { Degree } \\
\text { ays } \\
\left(D^{\prime} D^{\prime} s\right)\end{array}$} \\
\hline & $\begin{array}{c}\text { Duration of } \\
\text { generation } \\
\text { (days } \pm \text { S.E) }\end{array}$ & $\begin{array}{c}\text { Rate of } \\
\text { development \% }\end{array}$ & $\begin{array}{c}\text { Duration of } \\
\text { generation } \\
\text { (days) }\end{array}$ & $\begin{array}{c}\text { Rate of } \\
\text { development \% }\end{array}$ & & \\
\hline 20 & $65.51 \pm 0.56 \mathrm{a}$ & 1.53 & 62.50 & 1.60 & \multirow{4}{*}{12.03} & 522.11 \\
\hline 25 & $36.61 \pm 0.54 \mathrm{~b}$ & 2.73 & 38.46 & 2.60 & & 474.83 \\
\hline 30 & $27.98 \pm 0.49 c$ & 3.57 & 27.70 & 3.62 & & 502.80 \\
\hline 35 & $21.73 \pm 0.42 \mathrm{~d}$ & 4.60 & 21.69 & 4.61 & & 499.13 \\
\hline Average & & & & & & 499.71 \\
\hline L.S.D $1 \%$ & \multicolumn{6}{|c|}{2.47} \\
\hline
\end{tabular}

The values having the same letters vertically are non significant for different.

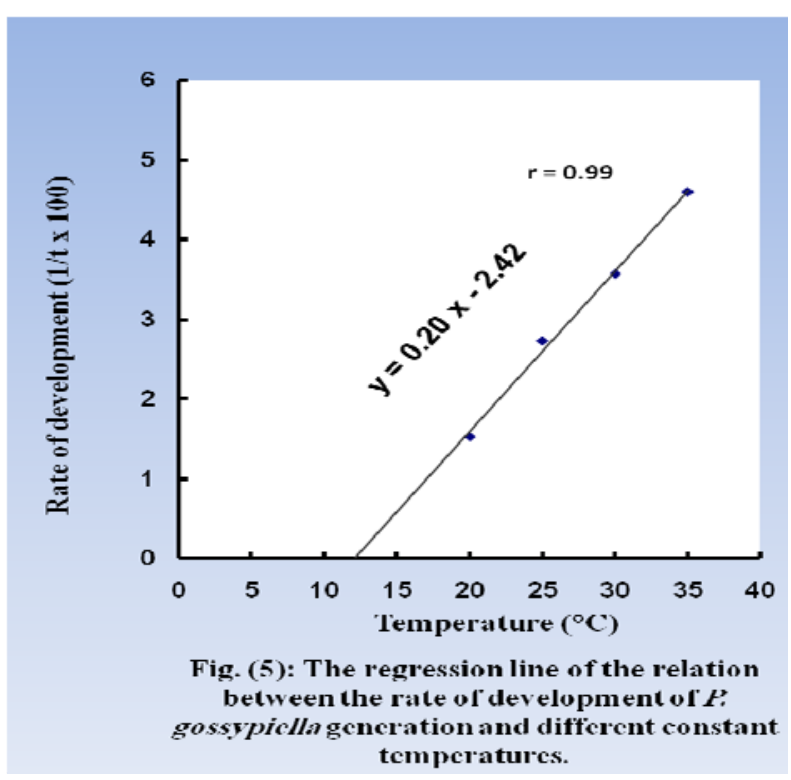




\section{REFERENCES}

Abdel-Hafez, A.; S. H. Taher; G. M. Moawad and KH. GH. El-Malki (1993): The combined effect of high temperature and exposure period regimes on some biological aspects of pink bollworm Pectinophora gossypiella (Saund.). Egypt. J. Appl. Sci., 8 (7): 485-493.

Blunk, M. (1923): Die Entwicklung Von Dytiscus marginalis L. Vom. Ei bis Zur Imago, 2 Teil. Die Metamorphase Zracht-Wiss. Sool, 121-171.

Dahi, H. F. (2003): Predicting the annual generations of the spiny bollworm Earias insulana (Boisd.) (Lepidoptera: Archtidae). Ph. D. Thesis, Fac. Agric., Cairo Univ., $182 \mathrm{pp}$.

Gergis, M. F.; M. A. Soliman; E. A. Moftah and A. A. Abdel-Naby (1990): TemperatureDevelopment relationship of spiny bollworm Earias insulana (Boisd.). Assiut J. Agric. Sci., 21 (3): 129-139.

Gergis, M. F.; M. A. Rizk; M. A. Makadey and A. Hussein (1994): Relationship between temperature and rate of development of cotton leafworm Spodoptera littoralis (Boisd.). Minia J. Agric. Res. \& Dev., 14

Hashem, M. Y.; I. I. Ismail; S. A. Emara and H. F. Dahi (1997): Seasonal fluctuations of the pink bollworm, Pectinophora gossypiella (Saund.) and prediction of generations in relation to heat unit's accumulation. Bull. Entomol. Soc. Egypt, 75: 140-151.

Kajanshikov, N.B. (1946): Kbonpocy oxnbhehhom tempnueckom ontnmyme 8olabnlbhoctn npuoueccob pazbntna hacekomblx bothowehnn tempnuecknx bilnahnn-300-Lx4 Prl. 25, C. 27-35.

Pedigo, L. P. (1991): Entomology and pest management text bood., Macmillan Publishing Company, New Your, pp.197-198.

Wagner, T. L.; H. I. Wu; P. J. H. Sharpe; R. M. Schoolfield and R. N. Coulson (1984): Modeling insect development rates: A literature review and application of a biophysical model. Ann .Entomol. ‘Soc. Amer., 77: 208-225.

\section{ARABIC SUMMARY}

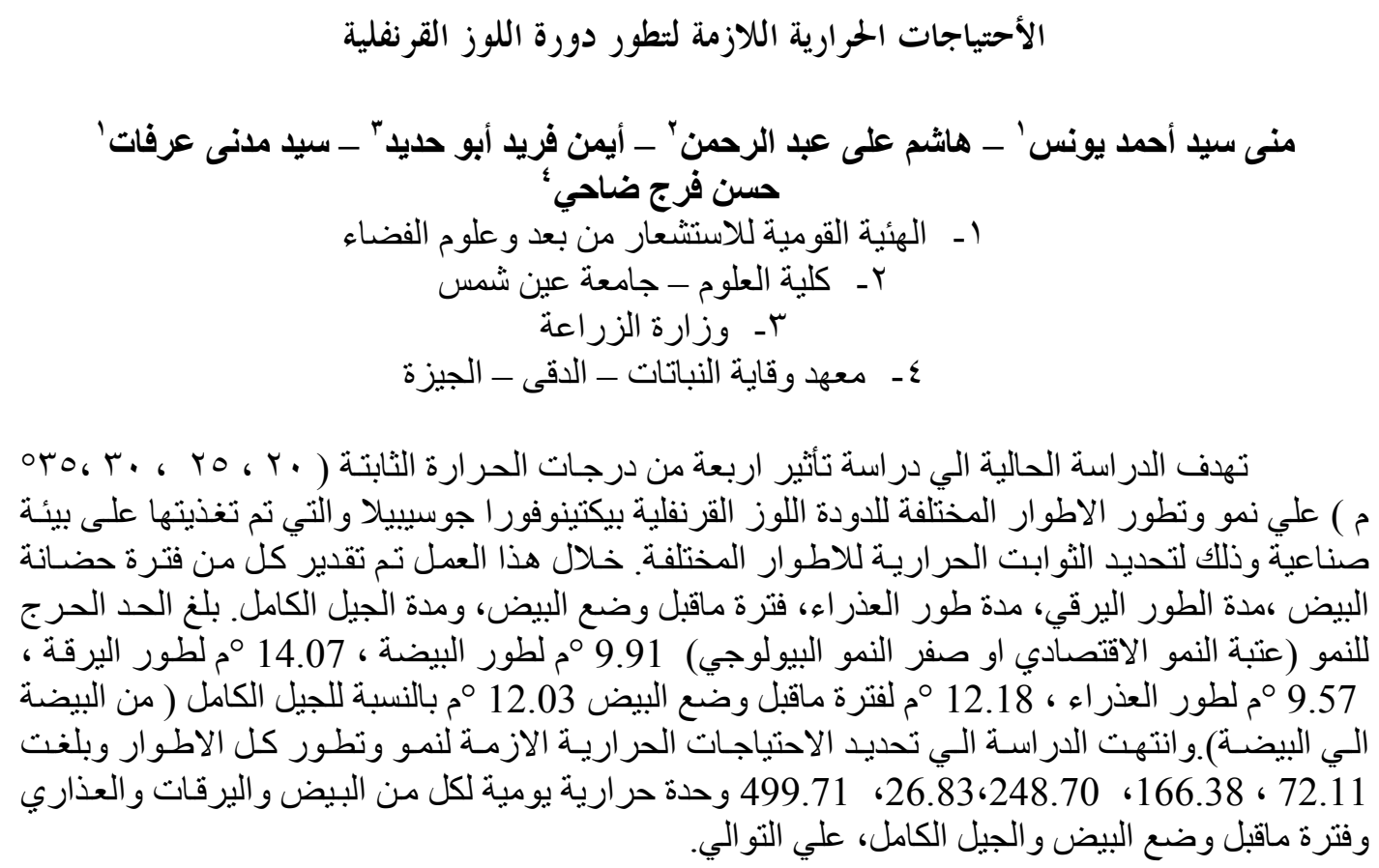

